\section{Resumo \\ Considerandoaimpatânia das interaçoes iniciais dbbebêcomo autro primordial, este artigo djeiva disatir as relações en- tre a consituição da represen- tação corparal ea construçãodo sujeto aprendente As autoras basciamse em contribuiçós de Paín (1973) e Fernández (1991; 2001) sdbre a fomm- ção de sintamas na aprendiza gemea dimensãocarparal, eem alguns teónicos da psicanálise que trabalham o aspecto constitutivodaimagemcorparal, comoDdto(1984) eAulagnier (1989), bemcomooapatefreur diano sobre a pulsão de saber (Freud, 1905). Disautem a impotância da constituição da representação corporal com partíipe da construção de mo dalidades de aprendizagem Descritores: constituição do corpa relaçós iniciais; sintoma na aprendizagem}

\title{
A DIMENSÃO DO \\ CORPO NA \\ APRENDIZAGEM
}

\author{
A ndrea Gabrida Ferrai \\ Regina O rger Sordi
}

\section{Intro d uçã o}

A Psicopedagogia trabalha com sujeitos, particularmente crianças que, por diferentes razões, são impedidas de se apropriar do conhecimento formalizado pela escola de maneira desejante. D eparar-se com essas dificuldades gera nos adultos uma série de sentimentos que vão desde 0 assombro/ perplexidade até a condenação da instituição escolar. 0 que faz com que uma criança não possa aceder a este conhecimento?

Cordiè (1996) aponta que o fracasso escolar entendido como um sintoma surgiu a partir da modernidade, em função das modificações econômicas e, consequentemente, do ideal social que preconizava a produtividade como o caminho natural do ser humano. No século XIX surgiu a escolaridade

- Psicóloga, Docente do Instituto de Psicologia da Universida de Federal do Rio Grande do Sul (UFRGS). 
obrigatória e, junto com ela, a necessidade de acompanhar um currículo escolar elaborado em função das novas tecnologias que atendiam ao ideário da produtividade. 0 não cumprimento desse novo ideal fez com que o fracasso se instalasse no âmbito da aprendizagem, visto que a constituição do sujeito pressupõe relações afetivas que estão necessariamente atravessadas pelas expectativas e exigências socioculturais.

Uma das abordagens possíveis para o entendimento do fracasso na aprendizagem ocorre a partir de uma intercessão de saberes oriundos da Psicanálise e da Psicopedagogia. É a partir deste pressuposto que trabalharemos as ideias deste texto.

Paín (1973) aponta que uma dificuldade de aprendizagem pode se expressar através de uma inibição ou de um sintoma. O sintoma aparece na obra freudiana como sendo uma formação de compromisso ou uma formação substitutiva, ou seja, um acordo entre as instâncias psíquicas para que uma moção pulsional seja descarregada pelo id, apesar das manifestações do superego. 0 ego se vê impelido a fazer um acordo entre ambos, deixando a moção pulsional ser descarregada, mesmo que deformada, tendo, como custo, parte de sua autonomia. Assim, em termos freudianos, somente poderíamos considerar sintomatológico um comportamento que se estabelecesse após a passagem pelo conflito edípico. Já, a respeito da inibição, Freud (1926, ci- tado por Paín, 1973) refere ser esta uma limitação normal de uma função que não carrega necessariamente um componente patológico. As funções egoicas que ele aponta passíveis de inibições referem-se à função sexual, função de nutrição, função de locomoção e à inibição do trabalho. Nesse sentido, a diferenciação entre inibição e sintoma refere-se à formação de uma nova operação psíquica, já que uma inibição pode se tornar sintomática desde que represente um conflito. Nesse sentido, Paín (1973) lembra que o sintoma seria a transformação de uma determinada função egoica.

O problema da formação de um sintoma na infância foi muito debatido pela Psicanálise. Muitos consideravam a impossibilidade de submeter uma criança a um atendimento psicanalítico, visto que, por não ter passado pelo conflito edípico, o comportamento inadequado não poderia ser considerado sintomatológico, uma vez que as três instâncias ainda não haviam se constituído (não esqueçamos que o superego é o herdeiro do Complexo de É dipo). Superada essa questão a partir do entendimento de que a criança faz sintoma onde 0 ideal parental de não castração falha (Melman, 1995), adentramos em um mundo no qual as representações da criança vão se formando a partir de representações que os pais encenam na interação (Aulagnier, 1990). Ou seja, a formação da representação da criança está influenciada por aquilo que o Outro primordial representa 
sobre ela; nesse sentido, pensamos que a formação do sintoma na criança também aponta para aquilo que, nascisicamente, os pais representam sobre a criança. Pensar a problemática da aprendizagem, quando esta se manifesta através de um sintoma, remete atentar não tanto aos conteúdos que não estejam sendo aprendidos quanto à operação cognitiva que esteja fraturada (Paín, 1973), na medida em que a mesma está relacionada ao não representado e não simbolizado ao nível da interação parental-filial.

Pelas razões expostas acima, pode-se dizer que a problemática que vai se desvelar na aprendizagem vem se estruturando no psiquismo da criança em um momento anterior à entrada na escola. É na escola que este sintoma se revela, mas resta perguntar: o que será que na história desse sujeito fez com que ele não possa saber? Será que se trata necessariamente de um segredo ou pode estar em jogo uma dificuldade no posicionamento como sujeito desejante desde as primeiras interações com os pais?

\section{A c onstituiçã o do c o rpo}

Freud (1921/ 1990a), iniciando suas investigações psicanalíticas com mulheres que sofriam sintomas histérico-conversivos, já se deparava com a dificuldade de diferenciar as instâncias somática e psíquica; de seus es- 
tudos clínicos, concluiu que o ego, em um primeiro momento, é um ego-corpo.

Para a psicanálise, a noção de corpo não é dada, mas construída na relação com o outro. Quando a criança nasce, não diferencia o que dela faz parte e do que dela não o faz. Para que isso aconteça, é necessário que esse organismo que nasce encontre um outro ser que lhe deposite e ofereça enunciados que o reconheçam como sujeito (Aulagnier, 1990). Nesse sentido, um organismo somente se torna um sujeito desde que tenha sido pensado, antecipado por outro (Aulagnier, 1989). D esde a concepção o feto é antecipado pelos pais como sendo alguém que possui características próprias que estão relacionadas aos desejos narcisistas desses pais. Assim, desde a gestação esse corpo que está por nascer é marcado a partir de enunciados que o antecipam como sujeito. Quando do nascimento, os pais precisam reorganizar seu bebê imaginado de acordo com as características do bebê da realidade (Horstein, 1994) para poder entrar em relação com ele, negociando, a partir de então, as expectativas narcísicas e idealizadas.

Paín e Jarreau (1996) apontam para uma diferenciação entre organismo e corpo. O rganismo refere-se a uma "estrutura material que conserva a estabilidade do ser humano através de uma programação reguladora. ... é capaz de registrar as coordenações sensório-motoras adquiridas de modo a que sejam utilizadas pelo sujeito de maneira automática ... é uma memória de funcionamento. A capacidade representativa só pode se desenvolver na condição de que uma parte de suas aquisições seja disponível sem passar pela consciência. ... Se o organismo pode ser comparado a um registrador, o corpo constitui um instrumento de música. Ele é o ato vivido, presença. $\mathrm{Na}$ arte 0 possível passa pelo corpo e esse por três planos" (p. 53).

O plano das coordenações sensório-motoras, o plano dos afetos, o plano da constituição do eu, todos em conjunto, participam da constituição do corpo. No primeiro plano, há uma coordenação entre as percepções e as ações que vão formando esquemas de ações e de significações. Por exemplo, o reconhecimento ocular de um círculo irá incluir o gesto para sua produção como possível traçado no papel. Para ser automatizado é necessário que, na execução de um gesto, o corpo encontre um máximo de eficácia e flexibilidade considerando os mecanismos de assimilação e acomodação descritos por Piaget (1971). 
Em relação ao plano dos afetos, precisamos considerar que, no corpo, a emotividade encontra ressonância. Esta é expressa em toda e qualquer produção considerando até as memórias mais primitivas inscritas no corpo. $O$ plano da constituição do eu relaciona-se à primeira imagem identificatória com ele mesmo. "Pode-se dizer que no início, o sujeito é seu corpo: não somente a forma de seu corpo como tal como ela lhe é restituída pelo espelho, mas, sobretudo, seu corpo eficaz, esse instrumento que obedece, quando ele quer alcançar alguma coisa. Portanto, toda representação assinala, ao mesmo tempo, um eu-proprietário (do corpo enquanto causa) e um eu-autor (da obra enquanto efeito)." (Paín \& Jarreau, 1996).

0 organismo é, então, considerado uma infraestrutura sensorial e de inscrição. 0 corpo é aquele que "toma corpo primeiramente na eficácia dos gestos aprendidos através dos quais se incorpora ao outro e domina a ação sobre os objetos e posteriormente em sua imagem estática em espelhos e retratos. $\mathrm{O}$ corpo será rapidamente instituído, simbolizado através de um nome e do uso de um pronome" (Paín, 1998, p. 6).

Paín (1973) refere que uma das condições internas da aprendizagem diz respeito ao "corpo como infraestrutura neurofisiológica ou organismo" (p. 25) que garante a conservação, coordenação dos esquemas e a dinâmica de sua disponibilidade atual, sendo necessário considerar " 0 corpo como mediador da ação e como assento do eu formal" (p. 25). É pelo corpo que o sujeito manifesta sua rigidez, flexibilidade, forma de caminhar, de pegar os objetos, ou seja, é com o "corpo que se aprende. As condições do mesmo - sejam constitucionais, herdadas ou adquiridas, favorecem ou retardam os processos cognitivos, especialmente os da aprendizagem" (p. 25).

Cabe ressaltar que Aulagnier (1990) refere que a relação psique-soma tem origem no empréstimo que a psique faz da atividade sensorial, sendo as primeiras representações produzidas a partir do material somático. Violante (2001), para explicar essa ideia, retoma o postulado piagetiano (Piaget, 1971) de que a inteligência, em um primeiro momento, é sensório-motora, ou seja, apoia-se nas percepções sensoriais. A criança, nesse período, organiza seu conhecimento através das informações que lhe chegam a partir do olfato, tato, paladar, sons, costurando-as visualmente pela observação do corpo do outro (não esqueçamos a necessidade da criança colocar os dedos na boca, nariz, olhos do adulto quando no início da constituição da diferença eu-outro). Violantelembra que, antes de constituir sua própria imagem, a criança precisa construir os primeiros esquemas vocais. Para que isso aconteça é necessário que, em um tempo anterior, ela tenha sido falada e tenha lhe sido acionado o desejo de escu- 
tar. Isso é fundamental, pois na medida em que a criança é convocada a escutar, vão sendo transmitidos os enunciados que a identificam como sujeito e, junto com isso, as interpretações sobre seu estado original, ou seja, sobre suas sensações corporais.

Inicialmente, então, a experiência somática se impõe sendo metabolizada em experiência psíquica. Nesse sentido sofrimento orgânico é sofrimento psíquico. Para que não tenha consequências avassaladoras, é necessário que esse sofrimento possa ser falado pelo outro no intuito de impedir o desinvestimento do corpo e do pensar. Assim, podemos perceber a relação das primeiras inscrições somáticas com esse inicio da representatividade e do pensar sobre. Se há algo que falha nessas primeiras inscrições do corpo, possivelmente haverá uma falha na capacidade do pensamento. Nesse sentido, o corpo é considerado, para Aulagnier (1990), um mediador entre duas psiques - a própria e a materna e entre a psique e 0 mundo.

$\mathrm{Na}$ clínica com crianças percebe-se o poder patogênico de algumas representações jogadas na criança quando bebê. Dolto (1992) refere que a imagem do corpo é testemunha das primeiras inscrições libidinais acontecidas na relação com o Outro primordial. Nesse sentido, a autora refere ser a imagem do corpo o todo vivido relacional, partindo de que a relação mãe/ bebê é fundamental e fundante do sujeito.
Para pensar na importância da representação do corpo na sintomatologia futura de uma criança se faz necessário diferenciar os conceitos de imagem corporal e esquema corporal. Esquema corporal é o corpo em si a partir do qual a imagem corporal vai se constituir. 0 esquema corporal é aquilo que nos define enquanto pertencentes a determinada espécie; é evolutivo e independe das relações com os outros e, assim "reporta 0 corpo atual no espaço à experiência imediata" (D olto, 1992, p. 15). 0 esquema corporal objetiva a intersubjetividade e, nesse sentido, pode ser 0 intérprete da imagem corporal. A autora enfatiza 0 vivido relacional da imagem corporal fazendo com que 0 corpo físico ou esquema corporal seja aquilo que vai possibilitar que a imagem corporal se estabeleça. É o estabelecimento da imagem corporal que possibilita a saída do homem biológico, como espécie, para o homem cultural. Isso implica na possibilidade de relacionar-se com o outro. Nesse aspecto, vemos como a concepção de organismo e corpo de Paín e Jarreau (1996) assemelha-se ao esquema corporal e imagem corporal de Dolto.

Dolto (1992) tem uma concepção muito particular do que pode ser considerado um bebê. Para a autora, 0 bebê é desde 0 início da sua vida um ser predisposto à comunicação, inserido desde o nascimento em relações linguageiras com aqueles que cuidam dele. Nesse aspecto, a autora insiste na necessidade de se falar com 
a criança, e até mesmo com um bebê recém-nascido, sobre tudo aquilo que o perturba ou faz sintoma. Ela parte do princípio de que 0 bebê entende absolutamente tudo 0 que um adulto entenderia. Nesse aspecto, não é necessário fazer adaptações nas palavras, mas entrar em comunicação com o bebê a partir e através da sua imagem corporal. Para a autora, imagem corporal é o todo vivido relacional de um sujeito e é considerada testemunha das inscrições libidinais do corpo na relação com o outro primordial.

Sendo assim, segundo a autora, é o circuito libidinal que responde pela condição de ser do sujeito, pois dá conta da busca constante de complementação. É o corpo que está subjacente a qualquer comunicação inter-humana, sendo o primeiro mediador entre o sujeito e 0 mundo.

O conceito de imagem do corpo derivou das observações da sua prática clínica com crianças neuróticas, da necessidade de utilizar algo que mediasse a criança e seu corpo (no adulto essa mediação acontece pela utilização da linguagem verbal) a partir do qual pudesse surgir material associativo que viabilizasse uma psicanálise. A eficácia na utilização de materiais gráficos e modelagens fez com que Dolto pudesse depreender dessa prática o conceito de imagem corporal, retirando o acento da clínica e ampliando-o para o entendimento da constituição subjetiva da criança na relação com 0 outro.

A imagem corporal muda em função das castrações. Segundo a autora, as operações psicológicas de castração humanizam as pulsões. 0 termo castração tem um significado bastante diferente daquele cunhado por Freud (1924, citado por D olto, 1992) e seguido pelos outros teóricos da psicanálise. Para D olto (1992), as castrações referem-se às provas que a criança deve passar ao longo da primeira infância para humanizar-se. São provações que acontecem na relação com o outro quando este a priva da satisfação corpo a corpo que até então lhe era permitida. A castração, então, lhe é possibilitada pelo O utro e é esta forma de doação que determinará como esta castração será recebida pela criança. Segundo a autora, para que uma castração não tenha consequências patogênicas, ela terá que necessariamente passar pela linguagem, garantindo, para a criança, a partir da mediação da palavra, a satisfação pulsional que está sendo interditada pelo adulto. Com isto percebe-se também a importância dos aspectos culturais na obra da autora, já que esses interditos não são caprichos dos adultos, mas acontecem porque também 
neles esta satisfação pulsional foi interditada, estando, os adultos, submetidos a essa ordem maior (ordem da cultura). Neste sentido fica bem marcado o poder humanizante das castrações. O utra questão fundamental é que a castração tem que ser dada e implica, por parte do outro, um ato de doação. Para que isto possa acontecer sem ambiguidades, aquele que oferece a castração também deve se sentir castrado, ou seja, impedido de que aquela satisfação aconteça no corpo a corpo com o bebê.

D olto (1992) desenvolve em sua teoria, consoante com o desenvolvimento psicossexual do indivíduo, 0 conjunto de castrações com as quais os sujeitos precisam lidar. Castração umbilical é aquela que ocorre no parto e funda o sujeito. Ela acontece nos dois polos da relação. Pelo lado dos pais acontece a renúncia do bebê imaginado, aceitando o estatuto civil e diferenciado desse novo sujeito. Do lado da criança acontece um deslocamento do cordão umbilical para a boca, o que implica em uma passagem de um tipo de existência fetal para um outro tipo de existência no qual as vias respiratórias são acionadas. Essa castração servirá de matriz para as castrações futuras. Nesse momento primordial, mãe e bebê transformam os comportamentos biologicamente preestabelecidos em comportamentos com algum sentido afetivo.

A castração oral refere-se ao desmame, o que impossibilita que a pulsão se satisfaça no corpo materno. Pode ser entendida como um prolongamento da castração umbilical, considerando o aspecto da separação corpo a corpo. 0 efeito humanizante dessa castração é a possibilidade da mãe não ser mais a única intérprete da linguagem da criança. O bebê começa a querer se comunicar sentindo muito prazer em brincar com os barulhos que saem da boca e estabelecendo longas conversas não somente com a mãe, mas, também, com seus brinquedos. Se estes brinquedos não tivessem sido apresentados seria impossível que o processo de olhar para outro lugar tivesse se iniciado. Não estaria aqui o esboço das futuras sublimações, tão necessárias para a aprendizagem formal? Não estaria aí o efeito das metabolizações maternas dos estados físicos do bebê?

No que concerne à castração anal, o que está em jogo é a interdição do prazer obtido pela manipulação materna no corpo da criança. A partir dessa castração a criança adquire autonomia motora, dispensando os cuidados dos adultos para alimentar-se, ir ao banheiro, vestir-se. A importância dessa castração está associada à maior independência dos cuidados da mãe, propiciando à criança 0 vislumbre da possibilidade de se independizar dos desejos maternos a seu respeito. 0 fator humanizante dessa castração refere-se à possibilidade de adquirir a noção adequada do que é lícito e ilícito e de não prejudicar os outros. Esse efeito humanizante se faz 
possível pela capacidade de maior domínio do corpo e a aquisição da noção dos limites físico-corporais. Além disso, pelo controle esfincteriano propriamente dito, a criança passa a saber que pode fazer determinadas coisas em determinados lugares e não em todos, como até pouco tempo atrás. Além dessas, temos, ainda, a passagem da criança pela experiência do espelho, ou seja, momento no qual ela se reconhece como sendo diferente daquilo que até então ela se pensava. A experiência do espelho é vivida pela criança também como castração humanizante, já que, por um lado, ela perde a possibilidade de confundir-se com os objetos do seu cotidiano; mas, por outro, vai adquirindo uma identidade. Nesta identidade, com certeza, estão colocadas todas as expectativas parentais e os resquícios das castrações humanizantes dos momentos subjetivos anteriores. D o ponto de vista psicopedagógico, a possibilidade de enunciar "eu", viabilizada pela passagem pelo espelho, potencializa a experiência de reconhecer-se autor de sua própria experiência.

\section{A c onstituiçã o do c orpo e a a prendizagem}

Fernandez (1991) refere que a aprendizagem organiza-se a partir de quatro níveis: a inteligência (autoconstruída na interação); o desejo (sendo desejo do desejo do outro); o orga- 
nismo (herdado e individual) e o corpo (construído especularmente).

A inteligência vai se construindo a partir dos esquemas sensório-motores, pela via das interações com os objetos oferecidos pelos outros e pela capacidade e possibilidade de manipulação desses objetos (Fernandez, 1991). "A inteligência tende a objetivar, a buscar generalidades, a classificar, a ordenar, a procurar o que é semelhante, o comum" (p. 73). Se, por um lado, a inteligência conforma a elaboração objetivante, 0 desejo conforma a elaboração subjetivante, pois faz com que cada pessoa tenha uma experiência única que está relacionada com a história afetiva e libidinal de cada um. Para D olto (1992) o desejo é acionado pela constituição da imagem corporal pelo testemunho das inscrições libidinais ou, como refere Aulagnier (1990), acionado pela colocação em cena e a apropriação dos enunciadosidentificantes oferecidos pelo O utro primordial. Por isso, desejo do desejo do O utro. Paín (1988) refere que, teoricamente, podem-se propor duas dimensões para a constituição do sujeito. Por um lado a inteligência, que sistematiza o conhecimento a partir da construção de um mundo coerente e objetivo. Por outro, a dimensão do desejo, a partir da qual o sujeito poderá instaurar 0 mundo intersubjetivo.

O organismo, como foi dito anteriormente, é considerado uma infraestrutura sensorial no qual a inscrição de um corpo vai se estabelecer.
Fernandez (2001) refere que a aprendizagem tem uma fonte somática e, de acordo com como o corpo foi constituído na relação com o outro, a criança terá uma modalidade própria do aprender. A importância do corpo para a aprendizagem refere-sea que é pelo organismo/ corpo que a criança entra em contato com o outro. A primeira experiência de satisfação (Freud, 1905/ 1990b) ocorre no momento em que a mãe, sentindo que seu filho lhe pede leite, oferece-lhe um para além. É por causa desse para além que a criança aceita, que poderá sair do estado de puro orgânico para encontrar a matéria-prima dos significados afetivos e culturais (Aulagnier, 1990).

Na medida em que a aprendizagem é um processo "cuja matriz é vincular e lúdica e sua raiz corporal" (Fernández, 1991, p. 48), seu desdobramento criativo vai se desenvolvendo pela/ na articulação da inteligência e do desejo e no equilíbrio das assimilações e acomodações.

"A modalidade de aprendizagem, tal como a entendo, é um molde relacional, armado entre a mãe como ensinante e o filho como aprendente, que continua construindo-se nas posteriores relações entre os personagens aprendentes e ensinantes (pais, irmãos, avós, vizinhos, grupo de pertencimento, meios de comunicação, professores) ao longo de toda a vida" (Fernandez, 2001, p. 66).

Existem dois processos de origem biológica que orientam a formação da modalidade de aprendizagem: 
a alimentação e o olhar. Em relação à alimentação, a autora refere que "é a fonte somática da modalidade de aprendizagem e das significações inconscientes do aprender" (p. 66), pois diz respeito ao investimento primordial desejante sobre aquele corpo.

"É necessário que o ensinante [mãe] experimente um prazer corporal (intelectual e desejante) com seus componentes de identidade ... para que 0 aprendente possa conectar-se com sua máquina desejante-imaginativa-pensante ... se [o ensinante] não experimenta prazer, se não há circulação de uma experiência de prazer comum pela via do corpo e de uma experiência de comunicação de autorias, o aprendente não receberá o 'conhecimento-prazer' de que necessita, numa forma apta para assimilá-lo e reconstituí-lo, isto é, aprendê-lo" (Fernandez, 2001, p. 67).

Para a autora, o significado da alimentação diz respeito às necessidades de incorporação e, nesse sentido, 0 aprender está inconscientemente ligado à alimentação; por sua vez 0 significado da fome está associado ao desejo de conhecer acionado pela função positiva da ignorância. Primeiramente, para saciar a fome/ aprender, é necessário que o outro lhe ofereça a comida/ conhecimento. Para assimilar a comida/ conhecimento, é necessário um comportamento ativo do bebê para transformar e incorporar o que lhe é oferecido. A digestão do alimento/ conhecimento é realizada pelas operações de seriação e classificação. 
Mas, para que a criança efetivamente aprenda, é necessário que o ensinante signifique aquilo que transmite como algo bom a ser oferecido para alguém significativo e único. Assim, o prazer sentido pelo ensinante é tomado pelo aprendente como desejo de conhecer e este prazer passa, necessariamente, pelo corpo.

Segundo a autora, se isso não ocorre "a inteligência tem disponível suas operações, mas o corpo, através do sintoma da aprendizagem (a inteligência e corporeidade aprisionadas), pode representar a permissão não outorgada e a não autorização do sujeito aprendente para recordar, manter, desfrutar e usar o conhecido, ou pode representar frustradamente, através da inibição cognitiva, 0 direito a não conhecer" (p. 69).

Com relação ao olhar, como base somática do aprender, Fernandez (2001) pensa em uma linha na qual, em um extremo se encontra "o exibir e 0 esconde, no centro situam-se 0 mostrar e 0 guardar; e, no outro extremo, marcando a patologia, junto ao exibir do ensinante, encontro o eitarodhardo aprendente, junto ao sonderdo ensinante o espiardo aprendente. Só frente ao mostrar-guardar do ensinante instala-se um espaço que permite aprender-olhar" (Fernandez, 2001, p. 70, grifos do autor).

Partindo do olhar que se estabelece entre ensinante e aprendente e tomando como base os quadros psicopatológicos da psicanálise, a autora aponta para tipos de vínculos específicos. 0 tipo de vínculo perverso se estabelece entre um ensinante que se exibe, mostra-se conhecedor e perverte 0 ensinar. Por sua vez, 0 aprendente inibe seu pensamento, expulsa e cospe o conhecimento. 0 tipo de vínculo neurótico refere-se a um ensinante que esconde um conhecimento secreto e um aprendente que somente pode conhecer espiando e perturbando o processo do conhecimento ou mesmo não mostrando o que aprendeu porque não está autorizado pelo ensinante. No processo neurótico, há um deslocamento da culpa do ensinante para 0 aprendente. No vínculo psicótico, 0 ensinante desmente 0 conhecimento formulado pelo aprendente que, por sua vez, pode não encontrar outra saída senão utilizar seu pensamento para alucinar ou anular sua capacidade pensante. Já no vínculo sadio, o ensinante mostra/ guarda o conhecimento sem culpa e conhece que desconhece. Isso permite que o aprendente se aproprie do conhecimento e possa efetivamente aprender.

A aprendizagem formalizada pela escola não acontece por fora das marcas das primeiras aprendizagens da criança a partir dos pri- 
meiros vínculos afetivos. A criança, nesse sentido, tende a repetir não somente os estilos e relacionamentos iniciais com os outros, mas, também, o estilo de aprender - somente pode aprender de acordo com as primeiras apresentações do mundo objetivo que foram metabolizadas e significadas a partir das inscrições libidinais.

Podemos pensar que é pela capacidade sublimatória materna que um sujeito surge e é penetrado pela linguagem, desenvolvendo as primeiras representações e, consequentemente, a renúncia do estado de infans Nesse sentido, a capacidade sublimatória materna é importante porque permitirá que ela deseje seu filho, não como instrumento de satisfação pulsional, mas como aquele que, colocado no lugar de ideal, poderá fazer e ser mais do que ela própria. É o olhar da mãe para outra direção, permitindo a entrada do objeto de conhecimento, que possibilitará que ambos saiam do êxtase narcísico, acionando a capacidade sublimatória na criança.

Ao nomear a criança, a mãe a limita, ao mesmo tempo em que oferece enunciados significantes palpáveis que passam a ser encenados na relação. Sabemos que o ato de nomeação permite 0 ingresso da criança ao mundo simbólico, momento no qual a mãe passa a pintar a tela (corpo do bebê) com as tintas (enunciados identificantes maternos) oferecidas pela sua história (parafraseando Aulagnier, 1990). Para que um eu se 
constitua é necessário que seja antecipado por outro. As primeiras manifestações do bebê colocarão à prova as emoções dessa mãe que terá o poder de modificá-las e isso transformará a expressão de necessidade do corpo do bebê em uma demanda a ela dirigida (Aulagnier, 1990). É justamente por esta intervenção do outro e a transformação do puramente orgânico que falamos em pulsão e não em instinto e, consequentemente, diferenciamos organismo de corpo e esquema corporal de imagem corporal.

Pulsão, considerada para Freud (1915/ 1990c) um conceito limítrofe entre o somático e o psíquico, diz respeito à inserção do organismo, biologicamente programado, em corpo, que sofre das sobre-determinações culturais trazidas pelos cuidadores primários. Para Freud (1905/ 1990b) existem duas pulsões que envolvem, desde seu início, outras pessoas como objetos sexuais - a pulsão de ver/ exibir e a da crueldade. Se bem que, posteriormente, elas se liguem à vida genital, no início aparecem como autônomas. É inegável que, para a criança pequena, não há motivo para a vergonha em relação ao seu corpo ou ao corpo do outro desnudo ou mesmo do ímpeto cruel em relação, por exemplo, a um inseto. A inibição frente à dor do outro se desenvolve tardiamente na criança. É necessário pensar na influência destas duas pulsões para 0 acesso ao conhecimento.

Freud, em Tresensayos detería se xual (1905/ 1990b) aponta para a re- lação da pulsão epistemofílica com as teorias sexuais infantis. A pulsão de saber não é considerada, pelo autor, como um componente pulsional elementar, nem pode ser totalmente subordinado exclusivamente à sexualidade. Esta pulsão trabalha com a energia da pulsão escópica e da forma sublimada do apoderamento do objeto. A atividade de investigação da criança é acionada, para Freud, pela ameaça da perda de amor da mãe pela chegada de um irmãozinho. Nem todas as crianças têm irmãos, mas a importância desta observação reside no fato de, em algum momento de nossas vidas, nos depararmos com a incógnita do nascimento e, consequentemente, do desejo do outro frente a nós mesmos. Para Freud a gênese da pulsão de saber encontra-se na pergunta sobre 0 nascimento das crianças. Esta pergunta pode estar ligada com a necessidade de dar conta da falta materna, justamente no momento em que a criança se depara com a perda da completude e da unidade eu-outro. Em termos lacanianos este fato está relacionado com o ingresso no É dipo, momento no qual a criança pergunta: o que afinal o outro quer de mim?, já que, se o outro quer, 0 outro deseja e, se deseja, não é completo. Para que esse movimento ocorra faz-se necessário que a mãe aponte para a falta, a qual, em um primeiro momento, encontra-se nela, pois muitas vezes não soube o que fazer com seu filho ou, simplesmente, voltou-se para outros interesses. Desde seus 
primórdios, a relação com o saber está relacionada com aquilo que Freud denominou de enigma da Esfinge.

As teorias sexuais infantis se impõem, para a criança, como forma de dar conta da incógnita do desejo da mãe. Nesse aspecto, Bergès e Balbo (2001) referem que a dúvida sobre 0 saber materno faz com que a criança construa uma hipótese que lhe permite montar sua teoria e, consequentemente, a mãe é capaz de se tolerar desconhecendo algo da sua criança. Assim, é como se fosse uma carta branca que a mãe lhe oferece de saber algo que ela própria não sabe. Como refere Aulagnier (1990), o saber sobre as origens está na origem do saber. Para que isto ocorra é necessário renunciar à certeza.

Bergés e Balbo (2001) referem que cada um de nós está preso à sua teoria, que não é geral, mas que instrumentaliza o sujeito na sua relação com 0 mundo e com a possibilidade de saber sobre si. As teorias sexuais infantis estão na origem, segundo os autores, do pensamento, da relação com a verdade e da necessidade de recalcar certas verdades. As verdades recalcadas são as respostas mentirosas que os adultos oferecem para as crianças e, estas, pela devoção ao adulto, acabam recalcando a hipótese tecida anteriormente. Este processo, por outro lado, pode instaurar algo fundamental para o pensamento - a dúvida. A dúvida nos faz continuar trilhando algo, nos faz continuar a pensar. 
Horstein (1994), apoiando-se em Aulagnier, refere que uma das funções do eu é o pensar, que se estabelece a partir dos enunciados identificantes oferecidos pelo outro materno. 0 pensar possibilita nomear imagens, afetos, refletir sobre si mesmo e se reconhecer pela possibilidade de assumir como seus alguns daqueles enunciados identificantes que o outro lhe ofereceu. Assim, "o que é dizível constitui a qualidade característica das produções do eu. Aquilo que não está enlaçado à representação de palavra não tem existência para o eu, o que não quer dizer que não sofra dos seus efeitos" (Horstein, 1994, p. 63). O eu, para enfrentar as mudanças do seu meio, lugar onde se encontram os objetos de prazer, vê-se condenado a investir. $\mathrm{O}$ eu é historiado, visto que é necessário ancorar-se em certos referentes (memória) que garantam a sua permanência. Isto é fundamental para poder investir na atualidade, tempo impossível de ser agarrado, mas que permite vislumbrar um futuro. Assim, a entrada na cena do eu refere-se à possibilidade deste ter sido, desde sua pré-história, historiado. 0 eu pode, então, metabolizar as representações fantasmáticas, transformando-as em representações relacionais. $\mathrm{O}$ eu faz um trabalho interpretativo da realidade que percebe, caso contrário, corre o risco de desaparecer.

"Estás condenado por e para toda a vida a uma colocação em pensamentos e em sentidos do teu próprio espaço corporal, dos objetos-meta de teus desejos, desta realidade com a qual deverás co-habitar, que lhe assegure para sempre permanecer como suportes privilegiados de teus investimentos" (Aulagnier, citado por Horstein, 1994, p. 67). "Este veredicto marca o eu desde seu surgimento na cena psíquica: pensar seu corpo, pensar seu estatuto desejante e a realidade que deverá proteger do risco do desinvestimento definitivo" (Horstein, 1994, p. 67).

Assim, a tarefa do eu é pensar, investir e sofrer: pensar e investir para não sumir da cena; sofrer é o preço a ser pago para se manter nela.

O processo secundário é caracterizado pela tentativa de estabelecer uma relação causal dos fenômenos que se apresentam para o eu. A interpretação elaborada e a colocação de sentido precisam ser garantidas pela verificação. A dúvida se instaura sendo, para Horstein (1990), o equivalente da castração. A partir de então, o eu poderá aceitar ou não uma ideia em função do prazer/ desprazer acarretado, mas precisará submeter esses enunciados à prova. Nesse processo, a instância terceira é colocada para desempenhar um 
papel de garantia. A dúvida instaura um processo de separação do "investimento da voz que enuncia, do investimento do enunciado" (Horstein, 1994, p. 70); assim, uma ideia aceita ou rechaçada não acontecerá pelo amor ou ódio sentido por determinada voz, já que a voz continuará sendo investida. $\mathrm{O}$ que será colocado à prova será a ideia enunciada por essa voz. Aqui se encontra a diferença entre sublimação e idealização. A criança, para poder pensar, precisa sublimar. A sublimação implica realizar certos ideais em nome próprio.

A sublimação pode ser considerada um destino da pulsão que é processada a partir da historicidade identificatória de um sujeito (Horstein, 1993). Ela permite que sejam deslocados, simbolicamente, os objetos primordiais. $\mathrm{O}$ autor refere que sublimação e idealização resultam de um trabalho psíquico de elaboração que separa a pulsão do seu apoio primitivo, conduzindo-a para outra direção. A diferença reside em que, na idealização, a modificação ocorre somente no objeto, sendo, então, considerada um fenômeno parcial.

Já na sublimação, algo especial ocorre com a finalidade e o objeto da pulsão: "Sem desaparecer, a sexualidade alcança um valor social e ético mais elevado. A sublimação somente pode ser definida pelas vicissitudes de uma história singular e pela valorização que uma atividade passa a ter por estar em concordância ou discordância com os valores coletivos ... A su- blimação, à diferença da adaptação, transgride frequentemente os valores que são admitidos no campo cultural. Por isso, uma das questões a desenvolver é o apoio, mas também a divergência, do ideal do eu com os ideais coletivos" (Horstein, 1993, pp. 60-61).

Uma questão importante para pensar a sublimação refere-se à dimensão estética como uma dimensão do pensamento. Nela a comoção nos envolve gratuitamente antes de poder codificar este aparecimento. Estes fenômenos simplesmente nos envolvem em uma dimensão afetiva harmônica com a nossa, mas que não é nossa (Paín, 1998). O u seja, podemos pensar em algo que está, ao mesmo tempo, fora e dentro de nós mesmos. Fora porque não é nosso, mas dentro porque conseguimos decodificá-lo e harmonizá-lo com nosso corpo. Algo similar ao processo de estranhamento (Freud, 1919/ 1990d), mas às avessas, pois gera em nós um dexar nos lexarpda situaçãa Esta noção de estrutura estética foi pensada, pela autora, a partir dos escritos de Meltzer \& Williams (1994), no qual a hipótese é de que, para o bebê saciado e relaxado, o mundo aparece-lhe como uma unidade que é esteticamente interessante. Disso decorre a disponibilidade do ser humano de captar as situações internas e externas harmonicamente.

A estética é considerada como uma estrutura própria do corpo que se encontra aquém da linguagem e da ação. 0 corpo, na dimensão estética, 
seria aquele que vivencia a presença atual das coisas. Tem a capacidade, por um lado, de ser capturado quando em tensão, o que permite o surgimento da emoção, e, por outro, de ser capturado quando distraído, o que permite a surpresa. A sensação estética passa necessariamente pelo corpo, pela capacidade deste de metabolizar as exigências do mundo, de dar um sentido ao que nos convoca. Assim, a função da dimensão estética do pensamento culmina, para Paín, em um pressentimento - sentimento prévio que permitirá significar o que vem de fora/ dentro.

Nesse sentido, não está "nem no pensamento lógico-simbólico nem no contorno marcado pelo horizonte histórico, mas, no encontro contingente mas não arbitrário do sujeito e o limite pensável para sua época. Não o limite entre o desejável e o proibido, que marca a distância do prazer à realidade, tão estudado pela psicanálise, mas o limite próprio ao im-previsível, ao im-prepensável, ainda que seja pela imaginação" (Paín, 1998, p. 11).

É por algo ser imprevisível e incognoscível que se permitirá pensar além da memória e das expectativas, permitindo que vários cenários se estabeleçam.

"Sem o fundamento estético a formulação do pensamento não sairia das suas dobradiças para ganhar espaços desmedidos e absurdos. A estética é a substância da ignorância que se orienta a uma manifestação enigmática" (Paín, 1998, p. 12). 
Nesse sentido, quando se pensa que a aprendizagem passa necessariamente pelo corpo, potencializa-se 0 seu sentido estético de ser o meio de captura da incógnita, da surpresa, do mistério. Não é à toa que Freud (1905/ 1990b) coloca que o que aciona a pulsão de saber na criança é a iminência da perda de amor da mãe que a retira do estado de êxtase e a convoca a tentar responder sobre 0 enigmada esinge, ou seja, todos os porquês possíveis eimpossíveis de serem pensados e não respondidos.

Assim, Horstein (1994) refere que na relação sublimada o objeto do pensamento é desejado por si mesmo, pois revela uma parte da verdade, não para impor ao outro uma rivalidade mortífera, mas para negociá-lo narcisicamente. 0 encontro com o pensamento do outro oferece um exemplo de prazer sublimado na atividade discursiva. "Nesses casos a comunicação repousa sobre um jogo identificatório onde os limites do narcisismo são superados em proveito de um funcionamento recíproco" (p. 58).

\section{C onc lusã o}

Pensar a aprendizagem como partícipe das origens do sujeito psíquico faz com que valorizemos suas múltiplas dimensões e compreendamos que, quando a criança chega na escola, grande parte de sua modali- 
dade aprendente/ ensinante já está constituída.

Por sua vez, é quando surgem sintomas que impedem as aprendizagens infantis de seguirem seu curso que se abre um terreno fértil para 0 reconhecimento da associação entre a capacidade de aprender conteúdos e o saber pessoal.

É no acento às modalidades de aprendizagem, constituídas nos vínculos iniciais ensinantes-aprendentes, que a Psicopedagogia oferece sua originalidade e especificidade como campo de compreensão do sintoma no aprender. Quando uma criança se encontra conflituada com suas aprendizagens é sua capacidade de argumentar, mostrar, ou seja, a elaboração objetivante, que fica impedida de se desenvolver, mas por impedimentos oriundos das significações inconscientes, que conformam a elaboração subjetivante. E é trabalhando permanentemente com a elaboração objetivante, contribuindo para o seu aparecimento, que a Psicopedagogia encontra o terreno fértil para ressignificar aquele sintoma que congelou as possibilidades aprendentes.

Se vamos a fundo à investigação dos sintomas na aprendizagem, deparamo-nos com que as representações que os pais têm a respeito dos mesmos estão amplamente ancoradas a fatos há muito ocorridos. Não raramente vemos explicações do tipo “ah, acho quenão consegue aprender porquea nota aquala [apgar] que des [os médicos] dãonopartonãofai 10 ... fá 9" , ou mesmo aquelas em que a problemática da aprendizagem está vinculada a um evento traumático que impede que a criança elabore o conflito e aceda ao saber: "o médico medissequede nãojunta asletrasparqueopai dlemmau quandbdetavana10-séiie... masdeémito inteligente, sónãoconsuejuntarasleras".

Fernandez (1991) refere que a capacidade para pensar resulta do entramado entre a inteligência e 0 desejo. Quando surge um problema na aprendizagem é porque o pensamento se submeteu ao desejo, ele foi aprisionado. Nesse sentido, Pain (1988) e Fernandez (1991) acreditam que o conteúdo ensinado na escola constitui um cenário simbólico que pode ser privilegiado para representar um conflito de ordem psíquica. A diferenciação entre estrutura afetiva e cognitiva, entre psique e soma, é possível somente pela estrutura de pensamento forjada no mundo ocidental. Temos a tendência de pensar de forma segmentada. 0 privilégio humano de relacionar-se, preferencialmente, a partir e através da linguagem teve como custo a impossibilidade de se apropriar do fenômeno total - para ser compartilhado com outro, ele precisa ser falado e, consequentemente, representado, acentuando alguns aspectos em detrimento de outros. $\mathrm{O}$ problema é que o surgimento de um sintoma nos confronta com essa dissociação, sendo necessário um novo entendimento por parte dos pais, das crianças e dos terapeutas que deem conta da falha doideal. 
A tentativa de entender a constituição do corpo, como sendo um dos principais lugares de inscrição do idkal, dá conta da necessidade de repensar o peso das interações iniciais o bebê com o outro primordial e 0 futuro surgimento de um sintoma de aprendizagem. Nesse sentido, poder pensar as modalidades de aprendizagem que se estabelecem entre 0 ensinante e 0 aprendente possibilita-nos recuar até as primeiras interações da mãe e a criança como sendo 0 protótipo do tipo de aprendizagens e ensinamentos futuros.

\section{THE BODY DIMENSION IN LEARNING}

\section{Abst RaCT}

Consideing the impatance of former interations between the baby and the primmodial dher this paper aims to disauss therdationship between the constitution of body representation and the constrution of the subjet of leaming Theauthors basethir idess on the contributions of Pain (1973) and Femándzz (1991;2001) abaut symptomformation in leaming and corporal dimension and some psychoanalytic devdopments about the constitutive aspet of body image such as Ddto (1984) and Aulagrier (1989), as well as thefreudian (1905) disussion abait the drive for knowing The authors disauss the impatance of the constitution of boody representation as partiapating in the construction of leaming modalities

Index terms: body consitition; former redationships; leaming symptom

\section{LA DIMENSIÓN DEL CUERPO EN EL APRENDIZAJE}

\section{RESUMEN}

Considerandb la impatania delas interaciones iniciales de bebécon e dro primurdial, ese

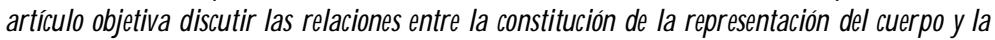
construción dd sujeo dd aprendzaje Las autoras basan sus idæas en las contribuciones de Paín (1973) y Femándz (1991; 2001) sdbrela formacón dd síntoma en d aprendzajeyla dimensión corporal yen algunosteéricos da psicoenálisis quetrabajan con d aspectoconsititivo dela imagen corporal, aś comod aportefreudiano(1905) sobrela pulsón dd saber. Disaten la impatania dela constituroón dela representación corporal como partíápedela construción demodalidades de aprendizaje

Palabras clave: consiturión da auepo pimeras rdaciones śntoma en d aprendizaje

\section{REFERÊNCIAS BIBLIOG RÁFICAS}

Aulagnier, P. (1989). O aprendiz dehistaiador eo mestreféticira do disarsoidentificante aodisarso ddirante São Paulo: Escuta.

(1990). Umintépreteembusca desentida São Paulo: Escuta.

Bergès, J. \& Balbo, G. (2001). A atualidadedas tecrias sexuais infantis Porto Alegre: CMC.

D olto, F. (1992). A imageminconsientedo corpa São Paulo: Perspectiva. 
Fernandez, A. (1991). A inteligênia aprisiona da: abordagempsicopeclagógica dínica da ciança esua família. Porto Alegre: Artmed.

(2001). A mulher escondida na professo ra: uma leitura psicapedagógica do ser milher, da corporidadeeda aprendizagm Porto Alegre: Artmed.

Freud, S. (1990a). El yo y el ello. In S. Freud, Obras completas (J. Etcheverry, trad., Vol. 19, pp. 1-66). Buenos Aires: Amorrortu. (Trabalho original publicado em 1921)

(1990b). Tres ensayos de teoría sexual. In S. Freud, Obras completas (J. Etcheverry, trad., Vol. 7, pp. 109-222). Buenos Aires: Amorrortu. (Trabalho original publicado em 1905)

(1990c). Pulsiones y destinos de pulsión. In S. Freud, Obras completas (J. Etcheverry, trad., Vol., 14, pp. 105-134). Buenos Aires: Amorrortu. (Trabalho original publicado em 1915)

(1990d). Lo ominoso. In S. Freud, Obras completas (J. Etcheverry, trad., Vol. 17, pp. 215-252). Buenos Aires: Amorrortu. (Trabalho original publicado em 1919)

Horstein, L. (1993). Pradica psicoanalítica ehis tóna Buenos Aires: Paidós.

(1994). Piera Aulagnier: sus cuestiones fundamentales. In Horstein, L. (O rg.) Cuerpo histaia, interpreación - Piera Aulagnier: de lo originario al proyecto indentificatorio (pp. 11-116). Buenos Aires: Paidós.

Melman, C. (1995). Sobre a educação das crianças. In Jerusalinsky, A. (O rg.). Educa se uma ciança? (pp. 31-42). Porto Alegre: Artes e Ofícios.

Meltzer, D. \& Williams, M. (1994). A apreensãodb bda opapd docanflito estético no desenvolvimento ma vidênia ena arte Rio de Janeiro: Imago.

Paín, S. \& Jarreau, G. (1996). Teria etémica da arteterapia, a compreensão do sujetta Porto Alegre: Artes Médicas.

Paín, S. (1988). Estruturas inconsientes do pensamenta Porto Alegre: Artes Médicas.
(2003). La Psicopedagogía em la actualidad. In Laino, D. (O rg.). La psicopedagoǵa emla adtualidad Buenos Aires: Homo Sapiens.

Piaget, J. (1971). Seis estudos de psicdoga. Rio de Janeiro: Forense.

Violante, M. L. (2001). Piera Aulagnier, uma contribuiçãocontemparân€à dora deFreud São Paulo: Via Lettera. ferrari.ag@hotmail.com sordi.voy@terra.com.br

Reedidoemmarç 2009. Acaitoemjulhd 2009. 